\title{
Custos no cultivo do tabaco: um estudo em uma pequena propriedade rural do sul catarinense
}

\section{Costs in tobacco cultivation: a study in a small rural property in the South of Santa Catarina}

\author{
Mérelin Becker Bacharela em Ciências Contábeis. Universidade do Extremo Sul Catarinense (UNESC) - Brasil. \\ eh_becker@hotmail.com \\ Januário José Monteiro Mestrando em Contabilidade. Universidade Federal de Santa Catarina (UFSC) - Brasil. \\ januariomonteiromonteiro@gmail.com \\ Eduardo Tramontim Castanha Bacharel em Ciências Contábeis. Universidade do Extremo Sul Catarinense (UNESC) - Brasil. \\ eduardo_tramontin@hotmail.com \\ Andreia Cittadin Doutoranda em Contabilidade. Universidade Federal de Santa Catarina (UFSC) - Brasil. \\ aci@unesc.net
}

\section{RESUMO}

O estudo tem como objetivo identificar os custos na produção de tabaco em uma propriedade rural do Sul Catarinense. Quanto à metodologia, caracteriza-se como qualitativa e descritiva, realizada por meio de estudo de caso, na forma documental e com entrevista semiestruturada. Para tanto, foram coletados os dados das notas fiscais de venda e de compra, bem como anotações do produtor da safra de 2017/2018. Os resultados apontaram que o processo produtivo possui três macroetapas, que foram denominadas de: a) Pré-plantio; b) Plantio, Cultivo e Colheita; c) Pós-Plantio. O maior gasto foi representado pela mão de obra, equivalente a $46,78 \%$ dos custos totais; o lucro obtido correspondeu a 17,03\% da receita; o Ponto de Equilíbrio Contábil encontrado foi de $\mathrm{R} \$ 37.880,57$; o Ponto de Equilíbrio Econômico não foi atingido, pois requeria o valor mínimo de venda de R\$ 101.843,36; a Margem de Segurança encontrada representou 36,31\% da receita total. Constatou-se que, no momento, o produtor não tem condições de reduzir seus custos fixos por esses serem compostos, principalmente, pela mão de obra própria e a depreciação. Conclui-se que a gestão de custos nas propriedades agrícolas é extremamente importante para obter melhores resultados, tendo em vista que essa atividade apresenta especificidades que não podem ser controladas pelo produtor rural.

Palavras-chave: Custos na Agricultura Familiar. Análise Custo, Volume e Lucro. Fumicultura.

\section{ABSTRACT}

The objective of this study was to analyze the costs of tobacco production in a rural property in the Southern region of Santa Catarina. It is qualitative and descriptive research, carried out through a case study, documentary research and semi-structured interview. For this, the data of the sales and purchase invoices, as well as notes of the producer related to the harvest of 2017/2018, were collected. The results showed that the production process has three macro stages: a) Pre-planting; b) Planting, Cultivation, and Harvest; c) PostPlanting. The largest expense was represented by labor, equivalent to $46.78 \%$ of total costs; the obtained profit corresponded to $17,03 \%$ of the revenue; the Accounting Balance Point found was R $\$ 37,880.57$; the Economic Equilibrium Point was not reached, as it required the minimum sale value of $R \$ 101,843.36$; the Safety Margin found accounted for $36.31 \%$ of total revenue. It was found that, at the moment, the producer is not in a position to reduce its fixed costs because these are mainly composed of own labor and depreciation. It can be concluded that cost management in farms is extremely important to obtain better results, considering that this activity has specificities that cannot be controlled by the rural producer.

Keywords: Costs in Family Agriculture. Cost, Volume and Profit Analysis. Tobacco Growing. 


\section{INTRODUÇÃO}

O setor do agronegócio tem sido motivado desde o surgimento do capitalismo e é um dos que mais cresce, procurando inserir o país no caminho da modernização agrícola (Hofer, et al., 2009). O modelo de agricultura familiar demonstra-se importante por promover uma economia alternativa, na qual o desenvolvimento é alcançado por meio da diversificação (Flexor e Grisa, 2012). Em razão dessa diversificação, de maneira específica esse artigo trata sobre a produção do tabaco, considerado por Samikwa, Brorsen e Sanders (1998) como uma commodities de difícil classificação, porém importante para a economia, haja vista a diversificação requerida para o crescimento da mesma, tanto local quanto nacional.

O Brasil foi considerado líder na exportação de tabaco em 2016, pois exportou 483 mil toneladas, que renderam US\$2,12 bilhões. A maior parte é cultivado na região sul, sendo que do montante produzido no país, essa é responsável por cerca de $98 \%$ do total e engloba 574 municípios dos 1.191 envolvidos. Segundo os dados de 2016, foram 144.320 famílias envolvidas na produção de tabaco no sul do país e, em 2017, o número de famílias sulistas produtoras cresceu para 150.240 (SINDITABACO, 2017; AFUBRA, 2018). Cruz (2018) afirma que o mercado do tabaco está em mudanças, uma vez que além do cigarro comum são utilizados outros produtos como cigarro eletrônico, vaporizadores, produtos de tabaco aquecido, que estão sendo desenvolvidos, como Produtos da Nova Geração. Nesse sentido, pode-se afirmar que o mercado do tabaco está em desenvolvimento com importante papel socioeconômico, pois gera vários postos de trabalho e movimenta as exportações.

Os dados apontam que a grande parte do fumo na região sul é produzido por pequenas propriedades familiares, no entanto a gestão dessas propriedades é ainda deficitária, uma vez que os custos agrícolas que envolvem a produção são poucos conhecidos, em vista disso a gestão dos negócios é comprometida (Clemente et al, 2012). Callado e Callado (1999) enunciam que a contabilidade rural é um instrumento administrativo pouco utilizado pelos produtores rurais. Porém, independentemente do meio que se insere, é necessária uma administração eficaz e participativa capaz de tornar a atividade rentável, mesmo em casos de pequenas propriedades rurais. Procópio (1996) afirma que embora os administradores rurais tenham relatórios contábeis, nem sempre possuem conhecimento adequado para interpretá-los a fim de tomar decisões. Alguns mantêm a Contabilidade apenas para fornecer dados na declaração de Imposto de Renda. E, embora necessite de muitas informações sobre desempenho, tanto físico quanto financeiro, o registro dessas informações está apenas em anotações informais ou na própria memória do produtor.

Nas propriedades rurais produtoras de tabaco localizados no sul de Santa Catarina essa situação não é diferente. A pesquisa de Hofer, et al., (2009) gerou insights para este estudo ao apontar como sugestão, mais pesquisas que tratem a análise do custo de produção de propriedades rurais, a partir da utilização de diferentes métodos e em diferentes atividades. Percebeu-se ainda mediante as buscas na literatura a carência de pesquisas que tratam sobre o custeio no âmbito do Agribusiness. Assim, tendo em vista a carência de conhecimento dos custos no meio rural, surgiu a seguinte questão de pesquisa: quais os custos envolvidos no cultivo de tabaco em uma pequena propriedade rural do sul catarinense? Para tanto, o objetivo consiste em identificar os custos na produção de tabaco da safra 2017/2018 em uma propriedade localizada no município de Timbé do Sul/SC.

O presente estudo se justifica pela contribuição teórica, dado que poucas são as pesquisas que tratam sobre o custeio na produção do tabaco (Hofer, et al.,2009). Neste contexto, mediante estudo qualitativo apresenta-se a realidade dos produtores rurais, logo o fato de não ser uma pesquisa atrelada a um grande produtor, permite agregar à literatura quanto ao entendimento sobre como os pequenos produtores e negócios se comportam. No âmbito prático, busca-se auxiliar o produtor rural no gerenciamento do negócio, visto que o preço do tabaco é determinado pelo mercado, por isso entender os custos de produção é de suma importância para obter melhores resultados. Acredita-se que ao oportunizar melhor controle dos custos, o 
produtor encontrará informações capazes de contribuir para redução dos gastos e consequentemente aumentar sua lucratividade. Clemente et al (2012) analisaram a percepção dos fumicultores em relação aos custos de produção, verificando que o controle dos custos é precário e que raramente é formalizado. Logo, esta pesquisa mostra-se relevante e pode auxiliar aos proprietários a não só aprimorarem a gestão de seus negócios como subsidiar ferramentas para formalizar a gestão.

No âmbito social pode-se perceber que a produção de tabaco é predominante na região e contribui com o fortalecimento os produtores, que resultará na geração de mais emprego e renda, logo a sociedade em geral se beneficia com esses. Nesse modo, esta pesquisa contribui à medida que os resultados podem levar os produtores a obter melhores resultados, refletindo na economia local e nacional como um todo.

Este artigo está estruturado da seguinte maneira: seção introdutória, seguido do referencial teórico, procedimentos e análises dos resultados e as considerações finais.

\section{FUNDAMENTAÇÃO TEÓRICA}

Stark (2007) afirma que o custeio variável é muito utilizado como instrumento para a tomada de decisão pelos gestores. Isso se deve, pois, esse método viabiliza a análise do custo-volume-lucro da empresa (Bornia, 2010). Nessa linha, aborda Wernke (2005) é essencial levar em consideração três elementos: i) Margem de Contribuição; ii) Ponto de Equilíbrio; iii) Margem de Segurança

A Margem de Contribuição Unitária, segundo Bornia (2010), é a parcela de preço de venda por produto que sobra para cobrir custos e despesas fixos e gerar lucro. A Margem de Contribuição Total do período é encontrada com o montante da receita diminuído dos custos e despesas variáveis totais. Quanto maior for o resultado encontrado da Margem de Contribuição melhor será para a empresa (Bornia, 2010). 0 Ponto de Equilíbrio ocorre quando a empresa produz o necessário para gerar receita equivalente ao valor dos custos, ou seja, não há lucro, mas também não há prejuízo (Dutra, 2003). Denota-se que o ponto de equilíbrio pode ser tanto contábil como já apresentado o conceito na frase anterior, financeiro que representa o valor capaz de cobrir todos os custos e despesas variáveis, bem como os custos fixos e as dívidas bancárias, exceto a depreciação que não se caracteriza como uma saída de recurso, e o econômico, que consiste em identificar a quantidade mínima que a organização precisa vender para obter o lucro desejado pelos proprietários. (Wernke, 2007)

O outro componente de custo/volume/lucro denominado Margem de Segurança (MS) representa o quanto as vendas podem cair sem haver prejuízo para a empresa. Esse indicador pode ser representado em valor, em unidade ou ainda em percentual (Bornia, 2010; Wernke, 2005). Esse conjunto de indicadores apresentado é necessário para determinar a influência no lucro, que são provocadas por alterações nas quantidades vendidas e nos custos (Bornia, 2010). A análise custo, volume e lucro é considerada também uma ferramenta indispensável para os gestores, pois gera diversas informações de cunho gerencial que contribuem para as empresas estarem a frente em mercados competitivos (Wernke, 2005).

Essa competitividade conforme Hofer et al., (2011) no gerenciamento de propriedades rurais se atenta a outros fatores como: ambientais, como estiagens, geadas, temporais; a lei da oferta e da procura, pois a variação de preços de produtos agropecuários, tem se tornado uma grande dificuldade para os proprietários rurais, ameaçando a permanência no campo. Destarte, na exploração rural de propriedades de pequeno e médio porte é muito comum a produção de várias culturas, paralelas à produção principal, geralmente necessárias para suprir a alimentação da família. Por isso, torna-se importante controlar os custos da propriedade a fim de evitar que determinada produção lucrativa mascare o mau desempenho de outra (Nepomuceno, 2004).

Nesse sentido, realizou-se um levantamento das pesquisas que abarcavam gestão de custos no setor agrícola com ênfase no custeio variável. Foi utilizado a base de dados do Congresso Brasileiro de Custos, que 
resultou em 94 estudos, dos quais foram selecionados 9 artigos que tratavam da aplicação do custeio variável na agricultura, no agronegócio e/ou no ramo agroindustrial. Os resultados são expostos na tabela 1.

\begin{tabular}{|c|c|}
\hline $\begin{array}{l}\text { Ducati } \\
\text { (1999) }\end{array}$ & $\begin{array}{l}\text { Objetivou mensurar os custos e determinar os preços de transferência para avaliar o } \\
\text { desempenho da empresa agroindustrial avícola. Concluiu que, além da utilização das } \\
\text { ferramentas calculadas mediante ao uso do custeio variável, a empresa deve adotar medidas } \\
\text { de avaliação não financeiras, que poderão proporcionar a melhoria constante. }\end{array}$ \\
\hline $\begin{array}{l}\text { Buarque e } \\
\text { Miranda } \\
(2000)\end{array}$ & $\begin{array}{l}\text { Objetivaram combinar o método de custeio variável na cadeia produtiva avícola em } \\
\text { Pernambuco. O método se mostrou o mais indicado para avicultura, por esta atividade } \\
\text { apresentar diversos custos variáveis na produção. }\end{array}$ \\
\hline $\begin{array}{l}\text { Ducati e } \\
\text { Bernardi } \\
(2005)\end{array}$ & $\begin{array}{l}\text { Demonstraram o uso do custeio variável em uma vinícola localizada no Vale do Itajaí/SC. } \\
\text { Como resultado verificaram que a margem de contribuição unitária maior é a do Vinho } \\
\text { Reserva, e que o vinho suave por ser o mais demandado contribui também para o resultado. }\end{array}$ \\
\hline $\begin{array}{l}\text { Faria, } \\
\text { Eyerkaufer e } \\
\text { Costa (2006) }\end{array}$ & $\begin{array}{l}\text { Identificaram e mensuraram os custos de produção de uma ovinocultura de corte em } \\
\text { Itapiranga/SC concluíram que o resultado econômico pelos dois métodos foi igual, porém, o } \\
\text { método de custeio variável é mais viável para os gestores da ovinocultura de corte tomarem } \\
\text { decisões de curto prazo. }\end{array}$ \\
\hline $\begin{array}{l}\text { Machado et } \\
\text { al. (2012) }\end{array}$ & $\begin{array}{l}\text { Aplicaram o custeio variável e o de absorção em duas fazendas de produção de leite em } \\
\text { Granada/MG. Como resultado, foi possível constatar prejuízo contábil nas propriedades } \\
\text { analisadas em ambos os custeios. }\end{array}$ \\
\hline $\begin{array}{c}\text { Gonçalves et } \\
\text { al. (2013) }\end{array}$ & $\begin{array}{l}\text { Buscaram avaliar se o método de custeio variável atendia às necessidades do gestor rural na } \\
\text { tomada de decisão, aplicado na Fazenda Surinan, localizada no munícipio de Fênix/PR. } \\
\text { Concluíram que foi possível a construção de ferramenta para apoio à decisão. }\end{array}$ \\
\hline $\begin{array}{l}\text { Schwert et } \\
\text { al. (2013) }\end{array}$ & $\begin{array}{l}\text { Buscaram valorar os produtos de uma propriedade rural localizada no município de } \\
\text { Dilermando de Aguiar-RS, utilizando o método de custeio variável. Constataram que as } \\
\text { atividades que mais geraram Margem de Contribuição Total foram a comercialização do } \\
\text { vinho, do suco de uva e a prestação de serviços }\end{array}$ \\
\hline $\begin{array}{c}\text { Fiorin, } \\
\text { Barcellos e } \\
\text { Vallim (2014) }\end{array}$ & $\begin{array}{l}\text { Aplicaram o custeio variável em uma agroindústria de laticínios em Alfredo Chaves/ES, para } \\
\text { servir de instrumento de tomada de decisão em um mix de produtos. Foi possível utilizar e } \\
\text { implantar a análise CVL (custo/volume/lucro), que contribuiu para praticidade e eficiência do } \\
\text { modelo de mix de produtos. }\end{array}$ \\
\hline $\begin{array}{c}\text { Cunha et al. } \\
\text { (2017) }\end{array}$ & $\begin{array}{l}\text { Analisaram, por meio do custeio variável, os resultados obtidos de uma vinícola localizada no } \\
\text { sul de Santa Catarina. Constataram que a vinícola não alcançou o ponto de equilíbrio em 2016, } \\
\text { necessitando reavaliar os custos de alguns produtos. }\end{array}$ \\
\hline
\end{tabular}

Tabela 1. Apresentação dos estudos anteriores.

Fonte: Elaborado pelos autores (2019)

\section{PROCEDIMENTOS METODOLÓGICOS}

Esta pesquisa caracteriza-se como descritiva e qualitativa, haja vista que descreve sobre uma realidade social a partir de um caso único. De acordo com Beuren et al (2006), pesquisa qualitativa realiza análises mais profundas e a descritiva - no olhar de Godoy (1995) - abrange dados descritivos sobre lugares, indivíduos e fenômenos. Dessa forma, esse artigo buscou descrever os custos incorridos na produção de tabaco em uma propriedade rural localizada no Sul Catarinense, a fim de propiciar a análise dos resultados.

Foi realizado um estudo de caso que, segundo Yin (2005), geralmente é utilizado quando o pesquisador tem pouco controle sobre os acontecimentos e quando o foco da pesquisa se insere em um contexto contemporâneo da vida real. Também se realizou pesquisa documental, em vista a análise de documentos que ainda não tinham recebido um tratamento analítico (Beuren et al, 2006).

Os dados coletados no estudo referem-se à produção de tabaco na safra de 2017/2018. O estudo de caso foi realizado em uma pequena propriedade rural localizada em Timbé do Sul em Santa Catarina. A 
propriedade possui área total de 7,5 hectares de extensão, sendo que aproximadamente 4,0 hectares são destinados ao plantio de tabaco, no qual ocorre a rotação de cultura com outros tipos de produtos como o milho e feijão. No período em análise foram plantados 58 mil pés de tabaco e colhidos aproximadamente 1.900 quilos por hectare. Cabe destacar que de abril a julho de 2017 ocorreu o preparo e cultivo das sementes nos canteiros e o preparo do solo. Também, no mês de julho de 2017 foi realizado o plantio das mudas de fumo no terreno. A partir desta data até outubro de 2017 houve o cultivo das plantas. Em novembro de 2017 iniciouse o período de colheita que encerrou em dezembro de 2017, a cura também foi realizada neste período. No período compreendido entre janeiro a março de 2018 realizou-se a classificação do tabaco para posterior venda.

A coleta de dados baseou-se nos seguintes documentos: notas de vendas e de gastos com a safra, como por exemplo, aquisição de sementes, combustível, fertilizantes e demais insumos, bem como as anotações do produtor rural. Durante o andamento da pesquisa foi realizado entrevista semiestruturada com o produtor no intuito de possibilitar a descrição de cada etapa do processo produtivo do tabaco., visto que conhecer as etapas do processo produtivo resulta na melhor alocação e identificação dos custos. Ademais, foi preciso identificar os bens que compõe o ativo imobilizado da propriedade para possibilitar o cálculo da depreciação.

\section{APRESENTAÇÃO E ANÁLISES DOS RESULTADOS}

A primeira etapa diz respeito ao processo produtivo do tabaco que começa com o Pré-plantio, macroetapa que se subdivide em Semeadura e Preparo do Solo. A segunda macroetapa foi denominada de Plantio, Cultivo e Colheita, que se configura pelo Plantio das Mudas, da Fertilização, Capinação, Desbrota e na Colheita das Folhas. Por último, ocorre a macroetapa do Pós-plantio que abrange a fase de Cura/Secagem das folhas e a Classificação. A Figura 1 evidencia o fluxograma do processo produtivo do tabaco.

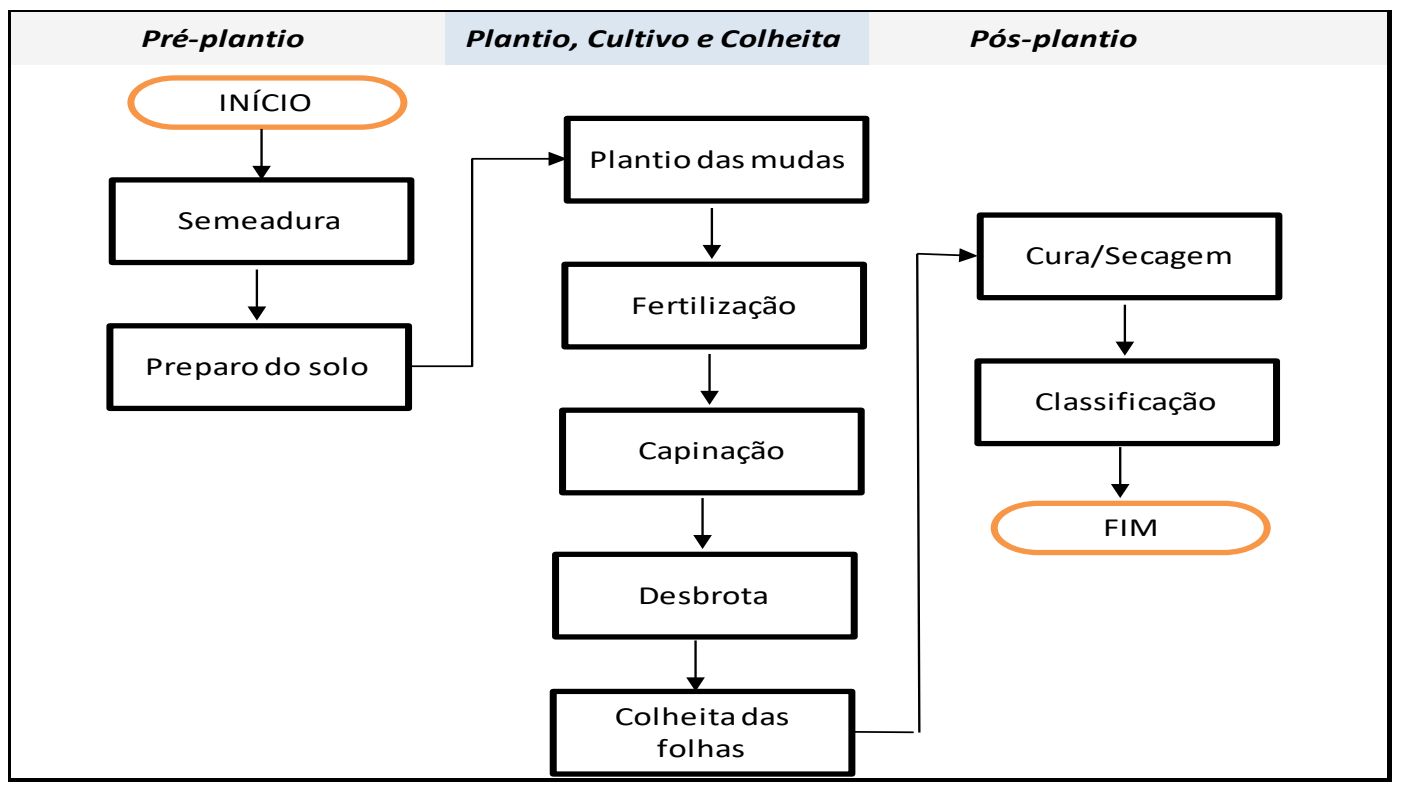

Figura 1. Fluxograma do Processo Produtivo do Tabaco

Fonte: Elaborada pelos autores (2019).

A macroetapa do Pré-plantio ocorre no momento em que o produtor prepara as sementes e o solo para o plantio das mudas. No preparo das sementes é realizada a semeadura, processo que é preciso primeiramente preparar os canteiros, que são como piscinas com água e adubo, para posteriormente as 
sementes serem colocadas nas bandejas de isopor. Os canteiros são uma espécie de túnel e devem ser confeccionados em locais que não tenha ventos fortes e de preferência longe de lugares sombrios. Esse processo de semeadura é conhecido como sistema Float ou Floating. Para tanto, faz-se uso de uma semeadeira que seleciona, em média, 1 ou 2 sementes para cada um dos espaços destinados às mudas nas bandejas. No sistema floating, as plantas em desenvolvimento recebem em torno de oito aplicações de pesticidas e fungicidas até atingir o ponto ideal para o plantio, entre cerca de 80 a 90 dias. Além disso, durante a fase de crescimento as plantas recebem três podas, para que seu caule se fortaleça e desenvolva folhas mais viçosas.

Concomitantemente ao desenvolvimento das mudas nos canteiros o produtor realiza a preparação do solo. Geralmente, efetua-se a aragem da terra, processo feito com o auxílio de um trator, que consiste em revirar o solo para que a terra fique mais solta. Após a aragem é necessário fazer os camalhões, que são elevações na terra destinadas ao plantio das mudas de tabaco. Destaca-se que no topo dos camalhões são aplicados fertilizantes e herbicidas. Com o solo preparado e as mudas desenvolvidas, inicia-se a macroetapa Plantio, Cultivo e Colheita, com a fase do plantio das mudas de tabaco. Para tanto, utiliza-se um equipamento operado de forma manual por uma pessoa enquanto outra é responsável por depositar as plantas em uma espécie de funil direcionado ao solo para o efetivo plantio. As mudas são plantadas com distância aproximada de $50 \mathrm{~cm}$ de uma planta a outra.

Enquanto a planta se desenvolve no solo o produtor precisa fazer novamente aplicações de herbicidas e pesticidas para evitar que ervas daninhas e pragas prejudiquem a plantação. A próxima etapa consiste na aplicação manual de fertilizante chamado de salitre, para fortalecer as plantas. Também, costuma-se realizar a etapa da capinagem, técnica que requer uso de enxada de forma manual para remover as ervas daninhas próximas às plantas. A fase de desbrota ocorre quando a planta começa a florir, em torno de 70 a 80 dias após a plantação. Com a retirada dos brotos e das flores das plantas de tabaco as folhas ficam mais viçosas, no intuito de obter melhor classificação e maior peso do tabaco depois de curado. Após a desbrota é aplicado o herbicida antibrotante que funciona como um selante, que impede o crescimento de brotos no local onde foram retirados.

Assim que as folhas atingem o ponto de maturação elas passam para a etapa da colheita, nesta fase as folhas são colhidas e levadas até a estufa de cura. Por fim, a macroetapa Pós-plantio inicia-se com a fase de secagem também conhecido como cura do tabaco, realizado em uma estufa. A estufa de cura pode ser convencional (modelo mais antigo e pouco utilizado nos dias atuais) ou eletrônica. Depois de curado, o tabaco é armazenado em um gal pão onde é realizada a última fase denominada de classificação e confeccionadas as manocas, que são agrupamentos de folhas da mesma classe, amarradas pelo talo de tamanho aproximado de $6 \mathrm{~cm}$ de diâmetro. A classificação é realizada conforme as folhas baixeiras, semimeeiras, meeiras e ponteiras e ainda observando a coloração. Após a elaboração das manocas de tabaco, estas passam pelo processo de prensagem, para confecção dos fardos.

Ao final desse processo os fardos são levados até a empresa compradora, que irá determinar a classificação final do tabaco. Destaca-se que o gasto do transporte do tabaco até a empresa compradora é de responsabilidade do produtor rural. A tabela 2 evidencia as principais classificações do tabaco.

\begin{tabular}{|c|c|c|c|c|c|}
\hline Folhas & Classes & Coloração & \multicolumn{3}{|c|}{ Grau de Coloração } \\
\hline \multirow{2}{*}{ Baixeiras } & \multirow{2}{*}{$X$} & $\mathrm{O}$ & 1 & 2 & 3 \\
\hline & & $\mathrm{R}$ & 1 & 2 & 3 \\
\hline \multirow{2}{*}{ Semimeeiras } & \multirow{2}{*}{ C } & $\mathrm{O}$ & 1 & 2 & 3 \\
\hline & & $\mathrm{R}$ & 1 & 2 & 3 \\
\hline \multirow{2}{*}{ Meeiras } & \multirow{2}{*}{ B } & $\mathrm{O}$ & 1 & 2 & 3 \\
\hline & & $\mathrm{R}$ & 1 & 2 & 3 \\
\hline \multirow{2}{*}{ Ponteiras } & \multirow{2}{*}{$\mathrm{T}$} & $\mathrm{O}$ & 1 & 2 & 3 \\
\hline & & $\mathrm{R}$ & 1 & 2 & 3 \\
\hline
\end{tabular}

Tabela 2. Principais Classificações do Tabaco

Fonte: Elaborado pelos autores (2019) 
As folhas baixeiras são geralmente classificadas como X, em seguida são analisadas as colorações que determina tipo $O$ para as folhas mais claras e $\mathrm{R}$ para folhas de coloração mais escuras; ainda há a variação da cor entre 1, 2 e 3 . As folhas semimeeiras usualmente são classificadas como $C$, também observando a cor clara e escura e o grau de coloração. As folhas meeiras, por sua vez, geralmente são classificadas como $B$, e as folhas ponteiras classificam-se como T. As melhores classes sempre têm combinação 01 para fumos claros e R1 para fumos mais escuros. Destaca-se que devido a qualidade do tabaco as folhas ponteiras, meeiras e semimeeiras costumam tem valor agregado maior, enquanto as folhas baixeiras têm o preço de venda reduzido.

Ressalta-se que pode haver outras classificações além dessas por influências de alguns fatores na etapa da colheita ou na secagem. Por exemplo, colher a folha que ainda não está madura ou não esperar a folha amarelar por completo na estufa de cura pode resultar em folhas esverdeadas depois de secas, resultando em enquadramento na categoria " $G$ ".

\subsection{Custos de produção}

A segunda etapa é a produção de tabaco, que requer diversos custos, entre esses podem ser citados os seguintes: mão de obra, depreciação das máquinas e equipamentos, combustível, sementes, adubos, fertilizantes, herbicidas e demais insumos. Observou-se que o produtor rural não considera a mão de obra própria como um custo de produção. Essa constatação vai ao encontro de Clemente et al (2012), que afirmam que na atividade agrícola é comum alguns custos serem negligenciados por não representar desembolso. Na propriedade em estudo a mão de obra é realizada principalmente pelo próprio produtor, que necessita em algumas etapas contratar mão de obra terceirizada. Dessa forma, para estabelecer o valor da mão de obra nesse estudo considerou-se o valor praticado na região para cada tipo de trabalho.

Destaca-se que o valor da mão de obra do produtor foi classificado como fixo, pois independentemente da quantidade produzida o agricultor necessita de uma remuneração; e o valor correspondente ao trabalho terceirizado foi considerado como variável, pois é contratado em determinadas etapas produtivas de acordo com a demanda de trabalho. Essa classificação vai ao encontro de Gonçalves et al. (2013), que afirma que a mão de obra do produtor independe da área de plantio, já a mão de obra terceirizada está diretamente ligada com a área cultivada.

Para um melhor entendimento, a figura 2 mostra o custo com mão de obra para cada etapa, com base no número de dias trabalhados.

\begin{tabular}{|c|c|c|c|c|c|c|c|}
\hline & Etapas & $\begin{array}{l}\text { Qtde de } \\
\text { Pessoas }\end{array}$ & $\begin{array}{c}\text { Dias } \\
\text { Trabalhados }\end{array}$ & \begin{tabular}{|c|}
$\begin{array}{c}\text { Valor por } \\
\text { dia }\end{array}$ \\
\end{tabular} & \begin{tabular}{|c|} 
Valor do \\
Trabalho \\
Terceirizado \\
/Variável \\
\end{tabular} & \begin{tabular}{|c|} 
Valor do \\
Trabalho \\
Próprio/Fixo
\end{tabular} & Total (R\$) \\
\hline \multirow{8}{*}{$\begin{array}{l}\frac{0}{\frac{0}{0}} \\
\frac{\pi}{0} \\
\frac{0}{0} \\
\frac{0}{0}\end{array}$} & Semeadura & & & & 210,00 & 280,00 & 490,00 \\
\hline & Plantio das sementes & 2 & 1,5 & 70,00 & 105,00 & 105,00 & 210,00 \\
\hline & Manejo herbicidas & 1 & 1 & 70,00 & 0,00 & 70,00 & 70,00 \\
\hline & Podas & 2 & 1,5 & 70,00 & 105,00 & 105,00 & 210,00 \\
\hline & Preparo solo & & & & 300,00 & 210,00 & 510,00 \\
\hline & Arragem do solo & 1 & 0,5 & 100,00 & 0,00 & 50,00 & 50,00 \\
\hline & Aplicação fertilizantes & 2 & 2 & 80,00 & 160,00 & 160,00 & 320,00 \\
\hline & Manejo herbicida & 1 & 1 & 140,00 & 140,00 & 0,00 & 140,00 \\
\hline
\end{tabular}

Continua 
continuando

\begin{tabular}{|c|c|c|c|c|c|c|c|}
\hline \multirow{15}{*}{ 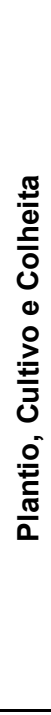 } & Plantio das mudas & & & & 350,00 & 850,00 & $1.200,00$ \\
\hline & Plantio mudas & 2 & 5 & 70,00 & 350,00 & 350,00 & 700,00 \\
\hline & Manejo pesticidas & 1 & 2 & 100,00 & 0,00 & 200,00 & 200,00 \\
\hline & Manejo herbicida & 1 & 3 & 100,00 & 0,00 & 300,00 & 300,00 \\
\hline & Fertilização & & & & 0,00 & 280,00 & 280,00 \\
\hline & Aplicação fertilizantes & 1 & 4 & 70,00 & 0,00 & 280,00 & 280,00 \\
\hline & Capinação & & & & 0,00 & 700,00 & 700,00 \\
\hline & Capinagem & 1 & 10 & 70,00 & 0,00 & 700,00 & 700,00 \\
\hline & Desbrota & & & & 0,00 & 900,00 & 900,00 \\
\hline & Desbrota & 1 & 5 & 80,00 & 0,00 & 400,00 & 400,00 \\
\hline & Manejo Veneno Antibrotante & 1 & 5 & 100,00 & 0,00 & 500,00 & 500,00 \\
\hline & Colheita das folhas & & & & $8.775,00$ & $1.350,00$ & $10.125,00$ \\
\hline & Colhedores & 3 & 13,5 & 170,00 & $6.885,00$ & 0,00 & $6.885,00$ \\
\hline & Operador Máquina Grampeadora & 1 & 13,5 & 140,00 & $1.890,00$ & 0,00 & $1.890,00$ \\
\hline & Operador trator & 1 & 13,5 & 100,00 & 0,00 & $1.350,00$ & $1.350,00$ \\
\hline \multirow{4}{*}{ 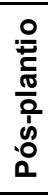 } & Cura/Secagem & & & & 0,00 & 600,00 & 600,00 \\
\hline & Operador fornalha & 1 & 10 & 60,00 & 0,00 & 600,00 & 600,00 \\
\hline & Classificação & & & & $3.000,00$ & $3.000,00$ & $6.000,00$ \\
\hline & Classificadores & 2 & 60 & 50,00 & $3.000,00$ & $3.000,00$ & $6.000,00$ \\
\hline \multicolumn{5}{|c|}{ TOTAL MÃO DE OBRA } & $12.635,00$ & $8.170,00$ & $20.805,00$ \\
\hline
\end{tabular}

Figura 2. Mão de Obra por etapa produtiva (valores em $\mathrm{R} \$$ )

Fonte: Elaborada pelos autores (2019).

Observa-se que o valor da mão de obra totalizou $\mathrm{R} \$ 20.805,00$ para essa safra, sendo que as etapas que apresentaram maior custo de mão de obra foram colheita das folhas, equivalente a $48,67 \%$ do total; seguida pela classificação, que representou $28,84 \%$ desse montante. Ressalta-se que $39,27 \%$ do total de mão de obra foram classificados como custo fixo, referente ao trabalho do próprio produtor rural e $60,73 \%$ classificado como custo variável, tendo em vista a mão de obra terceirizada.

Nota-se, também, que o valor do serviço por dia sofre variação conforme a atividade. Na etapa da semeadura, o valor pago para um dia de serviço correspondeu a $\mathrm{R} \$ 70,00$ para todas as tarefas. Para realizar as atividades nessa etapa foi necessária a contratação de uma pessoa para auxiliar no plantio das sementes. $\mathrm{O}$ manejo dos herbicidas foi realizado apenas pelo produtor, pois é uma atividade que requer menor tempo de trabalho. A poda das mudas ocorreu em três momentos e foi realizada pelo produtor e uma pessoa contratada.

No preparo do solo o produtor também contratou uma pessoa para realizar a aplicação do fertilizante adubo totalizando um gasto de $\mathrm{R} \$$ 160,00. Para o manejo do herbicida houve contratação de mão de obra que totalizou um gasto de R\$140,00. Da mesma forma, foi necessário contratar uma pessoa na etapa do plantio das mudas no solo pelo valor de $\mathrm{R} \$ 70,00$ ao dia, pois esta tarefa necessita ser realizada por duas pessoas.

Na etapa de colheita do tabaco além de requerer mais pessoas contratadas, o tempo para atividade é maior, de aproximadamente 13 dias e meio, e o valor pago por esse serviço na região é elevado, em torno de R\$ 170,00 por dia de trabalho. Foi necessário também a contratação de um operador de máquina grampeadora e/ou máquina de tecer, fatores esses que justificam o significativo valor da mão de obra nessa etapa.

O mesmo ocorreu para a fase de classificação do tabaco, na qual o produtor e uma pessoa terceirizada levaram sessenta dias para classificar, confeccionar as manocas e enfardar, que totalizou $\mathrm{R} \$ 6.000,00$ nessa fase. 
Outro custo fundamental para a apuração do resultado, porém geralmente não considerado pelos produtores rurais, corresponde à depreciação, pois não representa desembolso imediato (Clemente et al, 2012). Para identificar esse gasto, foi realizado junto ao produtor rural o levantamento dos bens, considerando a vida útil de cada item do imobilizado para definir a taxa de depreciação a ser utilizada. Por isso, foi questionado os valores pagos na aquisição e o tempo de vida útil ao proprietário. Verificou-se que o valor residual dos bens é igual à zero, pois na visão do proprietário os anos estimados de uso dos ativos é até o fim da vida útil de cada bem. Em seguida, calculou-se a depreciação referente cada item para o período em estudo, conforme evidenciado na Tabela 3.

\begin{tabular}{lrrrr} 
Item & Valor (R\$) & $\begin{array}{r}\text { Vida Útil } \\
\text { (a.a) }\end{array}$ & $\begin{array}{r}\text { Taxa (\%) } \\
\text { (a.a) }\end{array}$ & $\begin{array}{r}\text { Depreciação } \\
\text { Anual (R\$) }\end{array}$ \\
\hline Fornalha Estufa Convencional & & & $12,50 \%$ & 250,00 \\
Construção Estufa Convenc. & $2.000,00$ & 8 & $5,00 \%$ & 750,00 \\
Aparelho Elétrico Convenc. & $15.000,00$ & 20 & $10,00 \%$ & 35,00 \\
Fornalha Estufa Elétrica & 350,00 & 10 & $8,33 \%$ & 250,00 \\
Instalações Elétricas & $3.000,00$ & 12 & $14,29 \%$ & 714,29 \\
Construção Estufa Elétrica & $5.000,00$ & 7 & $1,67 \%$ & 333,33 \\
Galpão grande & $20.000,00$ & 60 & $1,82 \%$ & 909,09 \\
Galpão pequeno & $50.000,00$ & 55 & $6,67 \%$ & 666,67 \\
Máquina de Tecer & $10.000,00$ & 15 & $12,50 \%$ & 62,50 \\
Máquina Grampeadora & 500,00 & 8 & $4,00 \%$ & 16,00 \\
Grampos (380 un) & 400,00 & 25 & $4,00 \%$ & 152,00 \\
Máquina Plantio & $3.800,00$ & 25 & $16,67 \%$ & 13,33 \\
Prensa & 80,00 & 6 & $4,55 \%$ & 13,64 \\
Armário Defensivos & 300,00 & 22 & $5,00 \%$ & 35,00 \\
Enxada & 700,00 & 20 & $10,00 \%$ & 2,00 \\
Bandejas (360 un) & 20,00 & 10 & $10,00 \%$ & 144,00 \\
Trator & $1.440,00$ & 10 & $12,50 \%$ & $2.125,00$ \\
\hline & $17.000,00$ & & $\mathbf{6 . 4 7 1 , 8 5}$ \\
\hline
\end{tabular}

Tabela 3. Depreciação dos Bens

Fonte: Elaborado pelos autores (2019)

Nota-se que o valor da depreciação dos bens também é um custo significativo para a safra do tabaco e correspondeu a $\mathrm{R} \$ \mathbf{6 . 4 7 1 , 8 5}$ no período. Destaca-se que o valor da depreciação do trator é elevado por se tratar de um item de vida útil estimada em 8 anos, uma vez que foi adquirido usado. As construções da estufa elétrica e da estufa convencional, bem como o galpão pequeno e o galpão grande tem valores representativos de depreciação por serem ativos de alto valor, porém percebe-se que a vida útil desses itens é longa.

As fornalhas das estufas também têm grande representatividade no custo com depreciação por serem itens de menor tempo de vida útil comparado às construções. Destacam-se as instalações elétricas pertencentes a estufa elétrica, que se caracterizam, segundo o produtor, como uma casa de máquinas onde localiza-se os motores e os ventiladores da estufa e a depreciação correspondeu a aproximadamente $R \$ 715,00$ nessa safra.

Na Figura 3 são expostos esses valores correspondentes a safra pesquisada por etapa, com exceção da depreciação que foi alocada somente no Custo Total. 


\begin{tabular}{|c|c|c|c|c|c|c|c|c|c|c|c|}
\hline & \multicolumn{2}{|c|}{ Pré-Plantio } & \multirow[b]{2}{*}{$\begin{array}{c}\text { Plantio das } \\
\text { mudas }\end{array}$} & \multicolumn{3}{|c|}{ Plantio, Cultivo e Colheita } & \multirow[b]{2}{*}{$\begin{array}{c}\text { Colheita } \\
\text { das Folhas }\end{array}$} & \multicolumn{2}{|c|}{ Pós-plantio } & \multirow[b]{2}{*}{ Custos (R\$) } & \multirow[b]{2}{*}{ Custos (\%) } \\
\hline & Semeadura & $\begin{array}{l}\text { Preparo do } \\
\text { solo }\end{array}$ & & Fertilização & Capinação & Desbrota & & $\begin{array}{c}\text { Cura/ } \\
\text { Secagem }\end{array}$ & Classificação & & \\
\hline Sementes & 342,88 & & & & & & & & & 342,88 & $0,77 \%$ \\
\hline Turfa & 240,00 & & & & & & & & & 240,00 & $0,54 \%$ \\
\hline Fertilizantes & 16,50 & $3.410,00$ & & $3.569,94$ & & & & & & $6.996,44$ & $15,73 \%$ \\
\hline Fungicidas & 136,00 & & & & & & & & & 136,00 & $0,31 \%$ \\
\hline Pesticidas & 113,50 & & 80,00 & & & & & & & 193,50 & $0,44 \%$ \\
\hline Herbicidas & & 500,00 & 750,00 & & & 480,00 & & & & $1.730,00$ & $3,89 \%$ \\
\hline Mão de Obra & 490,00 & 510,00 & $1.200,00$ & 280,00 & 700,00 & 900,00 & $10.125,00$ & 600,00 & $6.000,00$ & $20.805,00$ & $46,78 \%$ \\
\hline Combustíveis & & 62,00 & & & & & 310,00 & & & 372,00 & $0,84 \%$ \\
\hline Lenha & & & & & & & & $4.800,00$ & & $4.800,00$ & $10,79 \%$ \\
\hline Energia & & & & & & & & $1.998,76$ & & $1.998,76$ & $4,49 \%$ \\
\hline Embalagem & & & & & & & & & 114,00 & 114,00 & $0,26 \%$ \\
\hline Terceiros & & 270,00 & & & & & & & & 270,00 & $0,61 \%$ \\
\hline Depreciação & & & & & & & & & & $6.471,85$ & $14,55 \%$ \\
\hline Custos (R\$) & $1.338,88$ & $4.752,00$ & $2.030,00$ & $3.849,94$ & 700,00 & $1.380,00$ & $10.435,00$ & $7.398,76$ & $6.114,00$ & $44.470,43$ & $100,00 \%$ \\
\hline Custos (\%) & $3,01 \%$ & $10,69 \%$ & $4,56 \%$ & $8,66 \%$ & $1,57 \%$ & $3,10 \%$ & $23,47 \%$ & $16,64 \%$ & $13,75 \%$ & $100,00 \%$ & \\
\hline Macro Etapa & 13,7 & $0 \%$ & & & $41,36 \%$ & & & 30 & $39 \%$ & & \\
\hline
\end{tabular}

Figura 3. Custos por etapas de produção

Fonte: Elaborada pelos autores (2019). 
Percebe-se que os custos da safra em estudo totalizaram $\mathrm{R} \$ 44.470,43$. A mão de obra representou $46,78 \%$ deste total, seguido pelo gasto dos fertilizantes (15,73\%), da depreciação $(14,55 \%)$ e da lenha $(10,79 \%)$. Ao analisar os custos por etapas, nota-se que a colheita das folhas representou $23,47 \%$ dos custos da safra, sendo que nessa etapa houve gastos de mão de obra mais expressiva e maior tempo de trabalho, além do elevado valor pago ao dia pela mão de obra terceirizada. Outras etapas significativas foram a cura/secagem por ter gastos expressivos de lenha e energia, representando 16,64\% do total; a classificação (13,75\%), pois há um grande gasto de mão de obra, justificado por ser uma etapa que levou 60 dias de trabalho de duas pessoas, como já destacado anteriormente; e, preparo do solo por ter altos gastos com fertilizantes, que representou 10,69\% do total. Analisando as macros etapas verificou-se que Plantio, Cultivo e Colheita têm maior representatividade por englobar os gastos expressivos de mão de obra da etapa da colheita.

\subsection{Análise dos resultados}

Após elencados os custos da safra realizou-se a análise custo-volume-lucro da propriedade empregando o custeio variável. A Tabela 4 traz as receitas auferidas pela venda do tabaco da safra de $2017 / 2018$ por classe do produto, obtidas conforme as notas de vendas do produtor rural.

\begin{tabular}{|c|c|c|c|c|}
\hline Classificação & Arrobas & $\mathbf{K g}$ & V. Unit. Por kg & Total \\
\hline BO1 & 94,44 & $1.416,6$ & 11,79 & $16.695,47$ \\
\hline T01 & 11,69 & 175,4 & 11,07 & $1.941,87$ \\
\hline CO1 & 70,34 & $1.055,1$ & 10,56 & $11.138,68$ \\
\hline BR1 & 53,39 & 800,8 & 9,16 & $7.332,44$ \\
\hline $\mathrm{CO} 2$ & 40,23 & 603,4 & 9,11 & $5.497,26$ \\
\hline TR1 & 7,49 & 112,4 & 8,69 & 976,76 \\
\hline XO2 & 18,48 & 277,2 & 7,76 & $2.151,07$ \\
\hline $\mathrm{CO} 3$ & 6,65 & 99,7 & 7,30 & 727,81 \\
\hline CR1 & 35,55 & 533,2 & 7,23 & $3.853,97$ \\
\hline XR1 & 2,96 & 44,4 & 6,78 & 301,03 \\
\hline BR2 & 7,17 & 107,5 & 6,70 & 720,25 \\
\hline XO3 & 5,92 & 88,8 & 6,23 & 553,22 \\
\hline CR2 & 43,46 & 651,9 & 5,14 & $3.350,77$ \\
\hline XR2 & 16,83 & 252,5 & 4,19 & $1.057,98$ \\
\hline TR3 & 11,14 & 167,1 & 3,43 & 573,77 \\
\hline CR3 & 2,89 & 43,3 & 3,30 & 142,89 \\
\hline XR3 & 58,25 & 873,8 & 2,47 & $2.158,29$ \\
\hline G3 & 19,58 & 293,7 & 1,02 & 299,57 \\
\hline TOTAL & 506,45 & $7.596,8$ & & $59.473,10$ \\
\hline
\end{tabular}

Fonte: Elaborada pelos autores (2019).

Percebe-se que o produtor vendeu cerca de 94 arrobas da classe BO1, totalizando R\$ 16.695,47; e, 70 arrobas de CO1 perfazendo o total de $\mathrm{R} \$ 11.138,68$. Essas classificações representam $46,80 \%$ das vendas totais, pois apresentaram maior valor agregado devido a qualidade. Porém, foram classificadas 58 arrobas de XR3 e 43 arrobas de CR2, que possuem preço de venda relativamente baixo, prejudicando a média geral do preço de venda. A tabela 5 apresenta o cálculo do preço médio de vendas por arroba e por quilo, calculado pela divisão da receita total pelo arrobas ou quilos vendidos.

\begin{tabular}{lc|l|c|c}
\hline \multirow{2}{*}{ Preço Médio por Arroba } & $59.473,10 \quad \mathbf{1 1 7 , 4 3}$ & $\begin{array}{l}\text { Preço } \\
\text { Médio por } \\
\text { Quilo }\end{array}$ & $59.473,10$ & \multirow{7}{7}{, $\mathbf{8 3}$} \\
\cline { 2 - 2 } & 506,45 & $7.596,80$ & \\
\hline
\end{tabular}

Tabela 5. Preço Médio por Arroba e por Quilo

Fonte: Elaborada pelos autores (2019). 
Percebe-se que o preço de venda apresentou variação de $R \$ 1,02$ a $R \$ 11,79$ e o faturamento do período refletiu em um preço médio de venda de $\mathrm{R} \$ 7,83$ por quilo. Esse valor poderia ter sido mais elevado se a classificação do fumo tivesse alcançado melhor qualidade na análise efetuadas pelas empresas compradoras. Com base no faturamento obtido e nos custos identificados na safra 2017/2018 elaborou-se a Demonstração do Resultado pelo Custeio Variável conforme mostra a Tabela 6.

\begin{tabular}{lrr}
\hline DR & $\mathrm{R} \$$ & $\%$ \\
\hline Receita Bruta & $\mathbf{5 9 . 4 7 3 , 1 0}$ & $\mathbf{1 0 0} \%$ \\
(-) Funrural (1,5\%) - INSS Produtor & 892,10 & $1,50 \%$ \\
(=) Receita Líquida & $\mathbf{5 8 . 5 8 1 , 0 0}$ & $\mathbf{9 8 , 5 0 \%}$ \\
(-) Custos Variáveis & $29.828,58$ & $50,15 \%$ \\
Sementes & 342,88 & $0,58 \%$ \\
Turfa & 240,00 & $0,40 \%$ \\
Fertilizantes & $6.996,44$ & $11,76 \%$ \\
Fungicidas & 136,00 & $0,23 \%$ \\
Pesticidas & 193,50 & $0,33 \%$ \\
Herbicidas & $1.730,00$ & $2,91 \%$ \\
Mão de Obra Variável & $12.635,00$ & $21,24 \%$ \\
Combustível & 372,00 & $0,63 \%$ \\
Lenha & $4.800,00$ & $8,07 \%$ \\
Energia & $1.998,76$ & $3,36 \%$ \\
Embalagem & 114,00 & $0,19 \%$ \\
Serviços de Terceiros & 270,00 & $0,45 \%$ \\
(-) Despesas Variáveis & 858,19 & $1,44 \%$ \\
Frete & 858,19 & $1,44 \%$ \\
(=) Margem de Contribuição & $\mathbf{2 7 . 8 9 4 , 2 3}$ & $\mathbf{4 6 , 9 0 \%}$ \\
(-) Custos Fixos & $14.641,85$ & $24,62 \%$ \\
Mão de Obra Fixa & $8.170,00$ & $13,74 \%$ \\
Depreciação & $6.471,85$ & $10,88 \%$ \\
(-) Despesas Fixas & $3.125,00$ & $5,25 \%$ \\
Pró-labore & $3.125,00$ & $5,25 \%$ \\
(=) Lucro da safra & $\mathbf{1 0 . 1 2 7 , 3 8}$ & $\mathbf{1 7 , 0 3 \%}$ \\
\hline
\end{tabular}

Tabela 6. Demonstração de Resultado Safra 2017/2018

Fonte: Elaborada pelos autores (2019).

Verifica-se que sobre a Receita Bruta tem-se a incidência do Funrural equivalente a 1,5\%. A Margem de Contribuição obtida após a diminuição dos custos e despesas variáveis correspondeu a 46,90\% na safra. Esses resultados foram similares aos achados de Ducati e Bernardi (2005) dado que ao aplicarem o uso do custeio variável na produção do vinho a margem de contribuição foi positiva. Destaca-se que a única despesa variável é o frete pago pelo produtor para levar o tabaco até as empresas compradoras. O valor desse frete varia de empresa para a empresa, mas ambas cobram com base no peso da carga.

O lucro da safra foi equivalente a $17,03 \%$ da receita bruta e foi obtido após a dedução dos custos e despesas fixas. Segundo o produtor este lucro poderia ter sido melhor caso a produção tivesse rendido mais em peso e qualidade; por determinados fatores o resultado da safra não foi conforme esperado, as empresas compradoras não classificaram o tabaco de acordo com o que ele entendia ser justo, fator que contribuiu para o resultado alcançado.

Destaca-se que o Pró-labore foi calculado com base nos valores do salário mínimo referente ao ano de 2017 e 2018. Logo, no ano de 2017 foram 9 meses com base de referência no valor correspondente a R\$ 937,00 e no ano de 2018 foram 3 meses considerando $\mathrm{R} \$ 954,00$. Dessa forma, os gastos de salário do produtor totalizaram $\mathrm{R} \$ 11.295,00$, sendo que os custos com mão de obra fixa totalizaram $\mathrm{R} \$ \mathbf{8 . 1 7 0 , 0 0}$ desse montante e a diferença foi alocada como Pró-labore em despesas fixas. Tal valor representa as despesas com deslocamento do produtor para comprar insumos e administração da propriedade. 
Destaca-se que a propriedade em estudo não possui gasto com Imposto sobre a Propriedade Territorial Rural - ITR, pois conforme a Lei n 9.393/96, Art. $2^{\circ}$ quando a propriedade for uma pequena gleba rural explorada somente pela família e o proprietário não possua outros imóveis o imposto não incide. Como o produtor de tabaco fica à mercê do valor determinado pelo mercado comprador, uma forma de aumentar seus lucros seria reduzir os gastos fixos da safra que corresponderam a 29,87\% da receita total. Porém, como estes custos são representados pela depreciação e a mão de obra do próprio produtor não é possível reduzilos. Uma alternativa seria modernizar o processo produtivo com novas tecnologias. Como afirma Santos et al. (2018) o uso da tecnologia no processo produtivo influencia positivamente no alcance do lucro. Tal influência é justificada dada que a medida em que a organização moderniza sua atividade otimiza os processos e alcança seus objetivos. Contudo, o produtor não possui recursos financeiros para este investimento no momento.

Para calcular o Ponto de Equilíbrio foi utilizado o índice da Margem de Contribuição de 46,90\%. A Tabela 7 apresenta o cálculo do PEC, PEF e PEE.

\begin{tabular}{lr}
\hline Ponto de Equilíbrio Contábil & \\
\hline Custos e Despesas Fixos & $17.766,85$ \\
(/) Índice da Margem de Contribuição & 0,4690 \\
(=) Ponto de Equilíbrio Contábil & $37.880,57$ \\
\hline Ponto de Equilíbrio Financeiro & \\
\hline Custos e Despesas Fixos & $17.766,85$ \\
(-) Depreciações & $6.471,85$ \\
(+) Dívidas do Período & 0,00 \\
(/) Índice da Margem de Contribuição & 0,4690 \\
(=) Ponto de Equilíbrio Financeiro & $24.081,99$ \\
\hline Ponto Equilíbrio Econômico & \\
\hline Custos e Despesas Fixos & $17.766,85$ \\
(+) Lucro Desejado & $30.000,00$ \\
(/) Índice da Margem de Contribuição & 0,4690 \\
(=) Ponto Equilíbrio Econômico & $101.843,36$ \\
\hline
\end{tabular}

Tabela 7. Ponto de Equilíbrio

Fonte: Elaborada pelos autores (2019).

Destaca-se que o produtor precisaria obter um faturamento de $\mathrm{R} \$ 37.880,57$ para não incorrer em lucro nem prejuízo, e ao desconsiderar a depreciação, tem-se um PEF de $\mathrm{R} \$ 24.081,99$. Foi ainda possível observar que para alcançar o lucro almejado de $\mathrm{R} \$ 30.000,00$ é necessário obter uma receita de $\mathrm{R} \$ 101.843,36$, não alcançada nessa safra.

Diminuindo o valor das Vendas Realizadas do Ponto de Equilíbrio Contábil encontra-se a Margem de Segurança. Este valor pode ser entendido como uma folga financeira, representando o quanto as vendas podem cair sem haver prejuízo. Na propriedade em estudo o valor encontrado foi de $\mathrm{R} \$ 21.592,53$ que representa 36,31\% da receita total na safra de 2017/2018. Esses achados vão ao encontro dos achados de Cunha et al. (2017) dado que os autores constataram que a empresa em análise não alcançou o ponto de equilíbrio desejado.

Depreende-se que o uso do custo variável auxilia na tomada de decisão, logo o produtor rural precisa se ater a esses pormenores a fim de que alcance o lucro. Esses achados de modo geral são convergentes com Gonçalves et al. (2013) por observarem que o custeio variável é uma importante ferramenta de apoio à tomada de decisão. Fato este que permite afirmar que em propriedade rural na qual o uso de ferramentas sofisticadas para gerenciar os custos é muitas vezes dificultado pela falta de recursos financeiros para tal, o uso do Custeio Variável é imprescindível. Faria, Eyerkaufer e Costa (2006) corrobora com estes argumentos ao afirmar que o método de custeio para o cálculo do custo de produção é um dos mais viáveis. Principalmente no que tange a pequenas e médias propriedades rurais. 


\section{CONSIDERAÇõES FINAIS}

A gestão de custo é um importante instrumento para planejamento e controle, bem como para busca da redução de custos nas organizações, sendo que nos empreendimentos agrícolas não é diferente. Para as propriedades de tabaco, conhecer e analisar os custos pode contribuir para reduzi-los e assim auferir maior lucro, já que o preço do tabaco é determinado pelo mercado.

Com a realização desse estudo verificou-se que o cultivo do tabaco requer 3 macroetapas, a saber: a) Pré-plantio; b) Plantio, Cultivo e Colheita; e, c) Pós- plantio. A primeira macroetapa caracteriza-se pelas fases da semeadura e preparo do solo; a segunda é composta pelo plantio das mudas, fertilização, capinação, desbrota e colheita das folhas; e, a terceira e última macroetapa inclui a secagem/cura das folhas e a classificação do tabaco. Quanto aos custos identificados no cultivo do tabaco, a mão de obra é o mais representativo em relação ao custo total, correspondente a $46,78 \%$ do total dos custos. A etapa da colheita foi a que apresentou maior valor de mão de obra em função do valor pago na região para essa atividade, seguida pela fase da classificação que necessitou cerca de 60 dias para ser finalizada.

Em relação à lucratividade da produção de tabaco da safra estudada, verificou-se que o lucro alcançado foi de $\mathrm{R} \$ 10.127,38$, que representa $17,03 \%$ da receita bruta de vendas. A margem de contribuição por sua vez representou $46,90 \%$ da receita total, com o montante de $R \$ 27.894,23$, sendo este o valor restante para quitar os custos e despesas fixas e obter o lucro da safra. O Ponto de Equilíbrio Contábil encontrado da safra foi de $R \$ 37.880,57$, valor capaz de cobrir todos os custos, porém não gera nenhum lucro. A diferença da Receita total com o PEC corresponde a Margem de Segurança no montante de R\$21.592,53 que seria a folga financeira da safra estudada. Um outro gasto que o produtor nunca considerou na apuração de resultados foi a depreciação dos equipamentos e construções, utilizada para cálculo do PEF que representou o valor de R\$ $24.081,99$. O PEE não foi alcançado, pois para isso as vendas deveriam totalizar no mínimo $\mathrm{R} \$ 101.843,36$, para trazer o lucro esperado.

O estudo realizado possibilitou o conhecimento dos custos e despesas da produção de tabaco por etapas, com isto foi possível averiguar as etapas da produção que possuem maiores gastos e considerar a mão de obra do produtor como um custo efetivo, já que o mesmo a desconsiderava. Também foram identificados os custos referentes à depreciação, gasto este nunca considerado antes pelo produtor, mas que representou $14,55 \%$ do total dos custos.

Notou-se a partir da análise custo-volume-lucro que o cultivo do tabaco nessa safra obteve baixa lucratividade, cerca de $17,03 \%$ da venda total, mas ainda assim foi suficiente para cobrir todos os gastos da safra 2017/2018, com margem de segurança relativamente alta de $\mathrm{R} \$ 21.592,53$. Percebeu-se que o produtor não consegue reduzir seus custos fixos, pois o que compõem os custos fixos da safra são a mão de obra do próprio produtor e a depreciação, sendo assim investir em tecnologias e modernização do processo produtivo seria uma alternativa, porém o produtor não possui recursos financeiros no momento. Depreende-se que o uso de tecnologia pode reduzir esses custos fato que gerará importantes implicações nos resultados da empresa. Essas implicações estão não somente atreladas ao alcance do lucro, mas também à aprendizagem organizacional.

A presente pesquisa avança em relação aos estudos (Ducati, 1999; Buarque, Miranda; 2000; Ducati; Bernardi, 2005; Faria; Eyerkaufer; Costa, 2006; Machado et al., 2012; Gonçalves et al., 2013; Schwert et al., 2013; Fiorin; Barcellos; Vallim, 2014) dado que foi desenvolvido em um contexto diferente do que pesquisas anteriores investigaram. E ao propor que uso do custeio variável é importante para a gestão das propriedades rurais que cultivam o tabaco, principalmente aquela de pequeno e médio porte, avança e contribui para a literatura sobre a temática. Gera também como implicações práticas a gestão do preço dos produtos e alcance do lucro, ao considerar que o uso custeio variável permite que a organização conheça seus custos e por sua vez possibilita melhor gestão dos preços.

Conclui-se que o uso da gestão de custos nas propriedades agrícolas é importante para obter melhores resultados, tendo em vista que esse tipo de atividade apresenta especificidades que não podem ser controladas pelo produtor, como preço de mercado, fatores climáticos e qualidade do produto. 
O estudo realizado apresentou algumas limitações tais como: o valor da mão de obra do produtor que foi estimado pelo preço pago na região; a depreciação que foi calculada com base nos valores e tempos de vida útil repassados pelo produtor; e, a análise dos resultados de um período, sendo que em algumas safras podem ocorrer outros gastos na lavoura.

Sugere-se para futuras pesquisas ampliar a análise dos gastos para outras safras, tendo em vista que, por exemplo, o preparo do solo requer reposição de nutrientes em determinados períodos incorrendo em outros gastos e podem ocorrer gastos com a manutenção dos equipamentos da propriedade. Também podese analisar a possibilidade de aumento da produção, caso o produtor decida atingir o Ponto de Equilíbrio Econômico.

\section{REFERÊNCIAS}

AFUBRA (2018). Fumilcultura no Brasil. Disponível em: https://afubra.com.br/fumicultura-brasil.html. Acesso em: 06 mar. 2018.

Brasil (1996). Lei No 9.393, de 19 de dezembro de 1996. Imposto sobre a Propriedade Territorial Rural - ITR. Disponível em: http://www.planalto.gov.br/ccivil_03/LEIS/L9393.htm. Acesso em: 10 dez. 2018.

Beuren, I. M., Longaray, A. A., Raupp, F. M., Sousa, M. A. B., Colauto, R. D., \& Porton, R. A. B. (2006). Como Elaborar Trabalhos Monográficos em Contabilidade. (3. ed.) São Paulo: Atlas.

Bornia, A. C. (2010). Análise Gerencial de Custos. (3. ed.). São Paulo: Atlas.

Buarque, R. C. S., \& Miranda, L. C. (2000). Identificação de um Método de Custeio para Apoio Gerencial da Cadeia Produtiva Avícola em Pernambuco com Ênfase na Margem de Contribuição e na Gestão Estratégica de Custos. In: Anais do Congresso Brasileiro de Custos-ABC. Disponível em: https://anaiscbc.emnuvens.com.br/anais/article/view/3110/3110. Acesso em: 24 maio 2018.

Callado, A. L. C., \& Almeida, M. A. (2005). Perfil dos artigos sobre custos no agronegócio publicados nos anais do Congresso Brasileiro de Custos. Custose @gronegócio on line, 1(1), Jan/Jun. Disponível em: https://s3.amazonaws.com/academia.edu.documents/18493949/perfil_de_publicacoes.pdf?AWSAccess Keyld=AKIAIWOWYYGZ2Y53UL3A\&Expires $=1523811262 \&$ Signature $=5 \mathrm{~s} \% 2$ F6LiYS7Db26w0\%2BISEQZM XfiV8\%3D\&response-content-

disposition=inline\%3B\%20filename\%3DPerfil_dos_artigos_sobre_custos_no_agron.pdf. Acesso em: 11 abr. 2018.

Callado, A. A. C., \& Callado, A. L. C. (1999). Custos: um desafio para a gestão no agronegócio. In: Anais do Congresso Brasileiro de Custos-ABC. Disponível em: https://anaiscbc.emnuvens.com.br/anais/article/view/960/960. Acesso em: 03 mar. 2018.

Clemente, A., Taffarel, M., Souza, A., \& Beledeli, A. M. (2012). Percepção dos custos, resultados e vantagens do cultivo de tabaco no centro-sul paranaense. Custos e @gronegócio on line, 8(4), out./dez. Disponível em: http://www.custoseagronegocioonline.com.br/numero4v8/Tabaco.pdf. Acesso em: 03 mar. 2018.

Cruz, S. (2018). Nosso Mercado: Importância Global. Disponível em http://www.souzacruz.com.br/group/sites/SOU_AG6LVH.nsf/vwPagesWebLive/DO9YDBC9?opendocu ment. Acesso em: 03 mar. 2018.

Cunha, P. M., Monteiro, J. J., Castanha, E. T., Menegali, M. V., Vieira, A. C. P., \& Cittadin, A. (2017). O uso do custeio variável para gestão de uma vinícola Catarinense. In: Anais do Congresso Brasileiro de Custos$A B C$. Disponível em: https://anaiscbc.emnuvens.com.br/anais/article/view/4376/4376. Acesso em: 24 mai0 2018.

Ducati, E. (1999). A avaliação de desempenho em uma empresa agroindustrial do ramo avícola. In: Anais do Congresso Brasileiro de Custos- $A B C$. Disponível em: https://anaiscbc.emnuvens.com.br/anais/article/view/3197/3197. Acesso em: 24 maio 2018.

Ducati, E., \& Bernardi, V. (2005). O uso do custeio variável em uma indústria vinícola. In: Anais do Congresso Brasileiro de Custos- $A B C$. Disponível em:

https://anaiscbc.emnuvens.com.br/anais/article/view/1894/1894. Acesso em: 24 mai. 2018.

Dutra, R. G. (2003). Custos:uma abordagem prática. (5. ed.). São Paulo: Atlas.

Faria, A. C., Eyerkaufer, M. L., \& Costa, A. (2006). Métodos de custeio por absorção e variável na ovinocultura de corte: estudo de caso em uma cabanha. In: Anais do Congresso Brasileiro de Custos-ABC. Disponível em: https://anaiscbc.emnuvens.com.br/anais/article/view/1731. Acesso em: 24 maio 2018.

Flexor, G., \& Grisa, C. (2012). Institutionalization of family farm policy in Brazil: history, ideas and actors. In Public Policies in Latin America and the Cognitive Approach: Paradigms, Actors and Coalitions. International Conference on Public Policy. Disponível em: http://www.icpublicpolicy.org/IMG/pdf/panel_26_s1_flexor_grisa.pdf. Acesso em: 24 maio 2018. 
Fiorin, I., Barcellos, S. S., \& Vallim, C. R. (2014). Gestão de custos através da análise CVL: Um estudo de caso em uma agroindústria de laticínios. In: Anais do Congresso Brasileiro de Custos-ABC. Disponível em: https://anaiscbc.emnuvens.com.br/anais/article/viewFile/3756/3757. Acesso em: 24 maio 2018.

Godoy, A. S. (1995). Introdução à pesquisa qualitativa e suas possibilidades. Revista de administração de empresas, 35(2), p. 57-63, mar./abr. Disponível em: http://www.scielo.br/pdf/rae/v35n2/a08v35n2.pdf. Acesso em: 28 abr. 2018.

Gonçalves, M. N., Oliveira, N. C., Baqueta, A. C. C., Ribeiro, R. R. M., \& Mattiello, K. (2013). Aplicação do custeio variável para o processo de tomada de decisão na produção agrícola: o caso da Fazenda Surinan. In: Anais do Congresso Brasileiro de Custos-ABC. Disponível em: https://anaiscbc.emnuvens.com.br/anais/article/viewFile/14/14. Acesso em: 24 maio 2018.

Hofer, E., Pacheco, V., Souza, A., \& Protil, R. M. (2011). A relevância do controle contábil para o desenvolvimento do agronegócio em pequenas e médias propriedades rurais. Revista de Contabilidade e Controladoria, 3(1), p. 27-42, jan./abr. Disponível em https://revistas.ufpr.br/rcc/article/view/21490/14140. Acesso em: 28 abr. 2018.

Hofer, E., Rauber, A. J., Diesel, A., \& Wagner, M. (2009). Gestão de Custos Aplicada ao Agronegócio: culturas temporárias. Contabilidade Vista \& Revista, 171), 29-46.

Machado, O. H., Souza, F. A., Costa, M. O., \& Mariano, F. O. (2012). Análise de custos e rentabilidade da produção de leite: um estudo em propriedades de Granada-Minas Gerais. In: Anais do Congresso Brasileiro de Custos-ABC. Disponível em: https://anaiscbc.emnuvens.com.br/anais/article/viewFile/212/212. Acesso em: 24 maio 2018.

Nepomuceno, F. (2004). Contabilidade rural e seus custos de produção. São Paulo: Thomson.

Procópio, A. M. (1996). Organização Contábil-Administrativa dos Produtores Rurais na Região de Ribeirão Preto. In: Marion, J. C. Contabilidade e controladoria em agribusiness. São Paulo: Atlas.

Samikwa, D. D., Brorsen, B. W., \& Sanders, L. D. (1998). Hedonic prices of Malawi burley tobacco. The International Food and Agribusiness Management Review, 7(1), 107-117.

Santos, T. O. et al. (2018). Reflexes of the automation technology in the economic results of integrated aviaries to a poultry company. Custos e Agronegócios, 14(2), p. 53-72.

Schwert, L. D., Cruz, V. R. L., Rossato, M. V., Guse, J. C., Freitas, L. A., \& Kesseler, N. S. (2013). Apuração de custos: uma análise em uma propriedade rural produtora de vinho e suco de uva. In: Anais do Congresso Brasileiro de Custos-ABC. Disponível em: https://anaiscbc.emnuvens.com.br/anais/article/view/16/16. Acesso em: 24 maio 2018.

Stark, J. A. (2007). Contabilidade de Custos. São Paulo: Pearson Prentice Hall.

SINDITABACO (2018). Perfis do produtor e da indústria. Disponível em: http://www.sinditabaco.com.br/sobre-o-setor/perfis-do-produtor-e-da-industria/. Acesso em: 06 mar. 2018.

SINDITABACO (2017). Sexto produto do agronegócio brasileiro, tabaco é exportado para 90 países. In: SindTabacoNews, 5. Disponível em:

http://www.sinditabaco.com.br/site/wpcontent/uploads/2017/05/SINDIfolderppp27A4.pdf. Acesso em: 03 mar. 2018.

Wernke, R. (2005). Análise de Custos e Preços de Venda. São Paulo: Saraiva.

Wernke, R. (2007). Avaliação da rentabilidade dos segmentos de mercado com o uso dos conceitos de margem de contribuição e valor presente: estudo de caso em distribuidora de mercadorias de pequeno porte. In Anais do Congresso Brasileiro de Custos- $A B C$.

Yin, R. K. (2005). Estudo de caso: projeto e métodos. Porto Alegre: Bookman. 